\title{
THE SURVIVAL ON SEED OF RHIZOBIUM MELILOTI FROM COMMERCIAL INOCULANTS
}

\author{
J. N. Parle, J. A. Douglas and T. S. Bailie* \\ Ruakura Agricultural Research Centre, Hamilton
}

\begin{abstract}
A survey of the numbers of viable Rhizobium meliloti recoverable from lucerne seed after inoculation by conventional methods with commercial inoculants has been carried out. Several batches of inoculant from manufacturers in New Zealand and Australia have been examined and, although all packs had high viable counts, in a number of cases very few live rhizobia could be recovered from seed one hour after inoculation.

It is suggested that poor survival of rhizobia on the seed surface is a cause of reported failures to establish luceme in both conventional sowings and oversowing trials.
\end{abstract}

\section{INTRODUCTION}

IN RECENT YEARS there has been increased interest in oversowing lucerne, particularly in South Island hill country (Douglas, 1970; Nixon, 1971; Jansen and White, 1971). In conjunction with field. trials on this subject the level of Rhizobium meliloti inoculant on the seed has been monitored to aid in the 'interpretation of the field results. On several occasions nodulation failures in the field were related to low counts of viable rhizobia in laboratory tests. In some situations, even though 30 to 40 times the recommended rate of inoculant was used, low numbers of viable rhizobia were recovered from the seed a few days after inoculation. Reports of nodulation failure in conventionally sown lucerne have also been received from farmers and farm advisory officers.

Following these results some doubt was cast on the efficiency of the lucerne inoculants used, a view also held by Jansen and White (1971). To investigate this problem, experiments were commenced at Ruakura to test the viability on seed of Rhizobium meliloti from some of the commercial inoculants available in New Zealand and Australia.

'Present address: Levin Horticultural Research Station, Levin. 


\section{MATERIALS AND METHODS}

Inoculants of Rhizobium meliloti from three manufacturers, two in New Zealand and one in Australia, were purchased from retailers throughout New Zealand or directly from the manufacturers. Each pack of inoculant made up in a peat base was suspended in sterile distilled water and agar cultures were suspended in reconstituted skim milk at the rate recommended by the manufacturers.

Samples were taken for counting the initial number of viable rhizobia in the inoculant as soon as an even suspension was attained. A further sample was used to inoculate $454 \mathrm{~g}$ of a single line of Wairau lucerne seed at the rate specified by the manufacturer. Immediately after mixing with inoculant the seed was spread to dry in a thin layer, kept shaded at all times and at a temperature of 18 to $20^{\circ} \mathrm{C}$. Inoculated seed was stored in the dark at room temperature.

All counts were made on duplicate samples of seed or inoculant. Counting: Each sample, $1 \mathrm{ml}$ of suspended inoculant or 100 seeds, was suspended in $100 \mathrm{ml}$ of sterile distilled water and shaken vigorously on a wrist action shaker for 20 minutes (Radcliffe $e t$ al., 1967). From this suspension a tenfold dilution series was prepared and four plant tubes at each level inoculated with $1 \mathrm{ml}$ of suspension (Date and Vincent, 1962). Plants were grown on for 6 weeks to allow nodules to develop and the number of viable rhizobia in the initial suspension estimated from a table of most probable numbers. All values given are average figures from the duplicate samples and duplicates never differed by more than one plant tube.

Dilution series were prepared so that numbers of rhizobia up to $173 \times 10^{6}$ for inoculant and $17.3 \times 10^{3}$ per seed could be counted. In one experiment glass beads were used in place of seeds: in this case inoculation and counting methods used were the same as for seed.

\section{RESULTS}

In the initial survey, packets of peat-based inoculant and agar cultures produced by one firm were obtained from various sources and the number of viable rhizobia initially present in the inoculant and on the seed after drying for one hour were determined (Table 1).

In all the samples tested the inoculant had a high level of viable rhizobia including the sample tested two months after its 
RHIZOBIUM SURVIVAL

TABLE 1

\begin{tabular}{|c|c|c|c|c|}
\hline $\begin{array}{l}\text { Batch } \\
\text { No. }\end{array}$ & $\begin{array}{l}\text { Expiry } \\
\text { Date }\end{array}$ & $\begin{array}{c}\text { Date } \\
\text { Counted }\end{array}$ & $\begin{array}{l}x 10^{6} / \mathrm{ml} \\
\text { Inoculant }\end{array}$ & $\begin{array}{c}\text { No. of Viable } \\
\text { Rhizobia/Seed }\end{array}$ \\
\hline 7011 & Jan. 1971 & Jul. 1970 & $>173$ & 163 \\
\hline $7006^{*}$ & May 1970 & Jul. 1970 & $>173$ & 103 \\
\hline 7015 & Jan. 1971 & Aug. 1970 & $>173$ & 581 \\
\hline 7026 & Feb. 1971 & Sep. 1970 & $>173$ & 17300 \\
\hline 7122 & May 1971 & Apr. 1971 & $>173$ & 17.3 \\
\hline 7203 & May 1972 & Mar. 1972 & $>173$ & 17300 \\
\hline Agar culture & - & Aug. 1970 & $>173$ & 4245 \\
\hline Agar culture & $\longrightarrow$ & Oct. 1970 & $>173$ & 220 \\
\hline
\end{tabular}

*Tested after expiry date.

expiry date and would be expected to provide at least 10000 viable rhizobia on the seed surface. However, in five of the eight packs examined, recovery of viable bacteria from the seed surface was much lower than expected.

A comparison was made between a batch of New Zealand inoculant and four packs from an Australian manufacturer (Table 2).

TABLE 2

\begin{tabular}{|c|c|c|c|}
\hline Source and Date Counted & $\begin{array}{c}\times 10^{6} / \mathrm{ml} \\
\text { Inoculant }\end{array}$ & No. of Viable & $\begin{array}{c}\text { Rhizobia/Seed } \\
24 h\end{array}$ \\
\hline New Zealand Oct. 1970 & $>173$ & 10300 & 1730 \\
\hline Australia Oct. 1970 & $>173$ & $>17300$ & 10300 \\
\hline Australia Jan. 1971 & $>173$ & $>17300$ & $>17300$ \\
\hline Australia Feb. 1971 & $>173$ & $>17300$ & $>17300$ \\
\hline Australia Jun. 1971 & 28 & 280 & 0 \\
\hline Repeat of June batch & 2 & 580 & 120 \\
\hline
\end{tabular}

Three of the Australian inoculant packs were of high quality but one had a lower initial count and gave poor survival on the seed surface. Similar results were obtained wih five batches of inoculant from a second New Zealand manufacturer (Table 3).

TABLE 3

\begin{tabular}{cccc} 
Date Counted & $\times 10^{6} /$ ml Inoculant & $\begin{array}{c}\text { No. of Viable } \\
1 \mathrm{hr}\end{array}$ & $\begin{array}{c}\text { Rhizobia/Seed } \\
24 \mathrm{~h}\end{array}$ \\
\hline Oct. 1970 & $>173$ & $>17300$ & 1730 \\
Apr. 1971 & 60 & $>17300$ & 42 \\
May 1971 & 65 & 115 & 8 \\
Mar. 1972 & $>173$ & $>17300$ & $>17300$ \\
Apr. 1972 & $>173$ & $>17300$ & $>17300$ \\
\hline
\end{tabular}


TABLE 4

\begin{tabular}{cc}
\hline $\begin{array}{c}\text { Time } \\
\text { after Inoculation } \\
\text { in hours }\end{array}$ & $\begin{array}{c}\text { No. of Viable } \\
\text { Rhizobia/Bead }\end{array}$ \\
\hline 0 & $>17300$ \\
1 & $>\mathbf{1 7} \mathbf{3 0 0}$ \\
2 & $\mathbf{5 8 1}$ \\
4 & 10 \\
6 & 5 \\
24 & 2 \\
48 & 10 \\
72 & 0 \\
Initial & $>\mathbf{1 7 3} \mathbf{x} \mathbf{1 0}$, \\
\hline
\end{tabular}

Inoculant from the pack obtained in April 1971 was used to examine the death rate of rhizobia when placed on the surface of glass beads (Table 4).

Although the recovery of viable cells immediately after inoculation and after drying was satisfactory there was again a rapid reduction in the numbers over the following 4 hours.

\section{DISCUSSION}

While the counting methods used here may not recover every rhizobial cell from the surface of a seed, techniques used in this study have been applied successfully elsewhere (Radcliffe et al., 1967), and the fact that in a number of cases almost all the 10-20 000 rhizobia/seed calculated to be present were found suggests that the counting method is reliable and the rapid reduction in viable cells shown is a real effect. There are numerous reports in the literature of rapid death of rhizobia on various surfaces (Vincent, 1958; Vincent et al., 1962; Date et al., 1965) but it is usually considered that peat-based inoculants give a considerable measure of protection to the rhizobia on the seed surface. It has also been demonstrated (Vincent, 1958; Taylor and Lloyd, 1968) that an initial high loading of rhizobia on the seed increased the time over which viable rhizobia can be recovered.

In this survey the level of viable cells in all the inoculants tested was high enough to provide approximately 10000 rhizobia/ seed at the rates of inoculation used. However, in a number of cases only a few hundred organisms could be found one hour after inoculation and in most cases studied the numbers continued to decline for at least the next 24 hours. The reasons for this rapid death rate do not appear to be associated with the toxic effect of the seed coat (Thompson, 1960) as all seed was drawn 
from one line and the death rate of rhizobia on glass beads was also very rapid. There was considerable variation amongst batches of inoculum in the number of rhizobia recovered from seed, but, since in no case were the numbers in the inoculant too low to provide an adequate loading on the seed, the rapid death of rhizobia is presumably due to lack of protection during drying. Since other workers have found that rhizobia on the seed suifacs can be protected by peat (Vincent, 1958), it seems possible that the pretreatment could have some effect on its protective ability. Roughley and Vincent (1967) found that pretreatment of peat had a marked effect on the viability of rhizobia during inoculant storage but there are no reports of the type of problem encountered in this survey.

Only a small sample of Australian inoculants could be obtained for testing in this survey and it would be desirable to conduct further comparative tests with the New Zealand manufactured ones. Three of the Australian packs were of very high quality and it is desirable to know whether the poor result with the fourth pack gave a reasonable estimate of the variability in the Australian material.

It is difficult to make precise statements on the number of viable rhizobia required on seed to give adequate nodulation in the field because this will depend on the conditions of soil and climate to which the seed is exposed. A general recommendation is that 100 viable rhizobia/seed are required to ensure adequate nodulation when planting in the most favourable conditions. Several thousand rhizabia per seed are needed when oversowing, and when seeds are likely to be exposed to sunlight for considerable periods (Date et al., 1965).

In this study, inoculant was obtained and seed inoculated in a practical manner. The wide variation in results indicates that, if the same inoculants had been used in field situations, some nodulation failures would be expected to occur, and, until the difficulties reported here can be resolved, oversowing lucerne into steep hill .country is likely to give variable results.

\section{ACKNOWLEDGEMENTS}

We wish to thank Field Research Officers for obtaining samples of commercial inoculant.

\section{REFERENCES}

Date, R. A.; Batthyany, C.; Jaureche, C., 1965: Proceedings of the 9th International Grassland Congress Brazil, 1 (2): 263-9. 
Date, R. A.; Vincent, J. M., 1962: Australian Journal of Experimental Agriculture and Animal Husbandry, 2: 5-7.

Douglas, J. A., 1970: Tussock Grasslands and Mountain Lands Institute Review, 20: 42-8.

Jansen, C. G.; White, J. G. H., 1971: N.Z. Journal of Agricultural Research, 14: 572-86.

Nixon, G. W., 1971: Proceedings of the Agronomy Society of N.Z., 1: 95-101.

Radcliffe, J. C.; McGuire, W. S.; Dawson, M. D., 1967: Agronomy Journal, 59: $56-8$.

Roughley, R. J.; Vincent, J. M., 1967: Journal of Applied Bacteriology, 30 (2): $362-76$.

Taylor, G. G.; Lloyd, J. M., 1968: Proceedings of the N.Z. Grassland As. sociation, 30: 154-63.

Thompson, J. A., 1960: Nature (London), 187: 619-20.

Vincent, J. M., 1958: In Nutrition of the Legumes (ed. Hallsworth), Butterworths, London. pp. 108-23.

Vincent, J. M.; Thompson, J. A.; Donovan, K. O., 1962: Australian Journal of Agricultural Research, 13: 258-70. 